Papers of the

East-West Population Institute, no. 33

\title{
The present and prospective state of policy approaches to fertility
}

by Ozzie G. Simmons and Lyle Saunders

干 EAST-WEST CENTER 
THE EAST-WEST CENTER is a national educational institution established in Hawaii by the United States Congress in 1960. Formally known as "The Center for Cultural and Technical Interchange Between East and West," the federallyfunded Center is administered in cooperation with the University of Hawaii. Its mandated goal is "to promote better relations and understanding between the United States and the nations of Asia and the Pacific through cooperative study, training, and research."

Each year about 1,500 men and women from the United States and more than 40 countries in the Asian-Pacific area exchange ideas and cultural insights in EastWest Center programs. Working and studying with a multinational Center staff on problems of mutual East-West concern, participants include students, mainly at the postgraduate level; Fellows with research expertise or practical experience in such fields as government, business administration, or communication; midcareer professionals in nondegree study and training programs at the teaching and management levels; and authorities invited for international conferences and seminars. These participants are supported by federal scholarships and grants, supplemented by contributions from Asian and Pacific governments, private foundations, and other agencies.

A fundamental aim of all East-West Center programs is to foster understanding and mutual respect among people from differing cultures working together in seeking solutions to common problems. The Center draws on the resources of U.S. mainland universities and Asian-Pacific educational and governmental institutions, as well as organizations in the multicultural State of Hawaii.

Center programs are conducted by the East-West Communication Institute, the East-West Culture Learning Institute, the East-West Food Institute, the East-West Population Institute, and the East-West Technology and Development Institute. Open Grants are awarded to provide scope for educational and research innovation.

THE EAST-WEST POPULATION INSTITUTE, established as a unit of the East-West Center in 1969 with the assistance of a grant from the Agency for International Development, carries out multidisciplinary research, training, and related activities in the field of population, placing emphasis on economic, social, psychological, and environmental aspects of population problems in Asia, the Pacific, and the United States. 
The present and prospective state of policy approaches to fertility

by Ozzie G. Simmons and Lyle Saunders

Number $3 \hat{3} \bullet$ June 1975

PAPERS OF THE EAST-WEST POPULATION INSTITUTE 
OZZIE G. SIMMONS is Regional Program Officer, Population and the Social Sciences, The Ford Foundation, Bangkok, Thailand. LYLE SAUNDERS is Program Officer, Population Office and Office for Asia and the Pacific, The Ford Foundation, New York, New York.

\section{Library of Congress Cataloging in Publication Data}

Simmons, Ozzie G

The present and prospective state of policy approaches to fertility.

(Papers of the East-West Population Institute ; no. 33)

A shortened version of a paper originally prepared for a meeting of the Ford Foundation's international population staff held at Cali, Colombia, Oct. 14-18, 1974.

Bibliography: p. 23-25.

1. Population policy-Congresses. 2. Fertility, Human-Congresses. I. Saunders, Lyle, joint author. II. Title. III. Series: East-West Population Institute. Papers of the East-West Population Institute ; no. 33. 
CONTENTS

Preface $v$

Abstract $\quad 1$

Introduction $\quad I$

Fertility policy: concepts and definitions 5

Policy measures amenable to governmental action $\quad 9$

Recent population and development policies 10

Policy analysis 15

Policy research 18

Conclusion 20

References 23 
PREF ACE

This paper was originally prepared for a meeting of the Ford Foundation's international population staff held at Cali, Colombia, 14-18 October 1974. The present version has been somewhat shortened but in substance is essentially the same as the one presented at the Cali meeting. In preparing the paper we received valuable advice and criticism from our Foundation colleagues Oscar Harkavy, Michael Teitelbaum, Adrienne Germain, and Robert Wickham and from Warren Robinson, Population Council, Bangkok. To all of them we are grateful.

Ozzie G. Simmons

Lyle Saunders 

ABSTRACT Concepts and definitions of population policy are reviewed and a formulation is proposed to distinguish policies explicitly oriented to the goal of reducing fertility from other policy approaches that claim to have effects on fertility. The types of policy measures adopted by governments to reduce fertility are few in number. of which family planning is the most common.

There is need, consequently, to identify and assess the range of alternative policy options for reducing fertility, in addition to family planning. that could be adopted and implemented by governments now to slow down population growth as soon as possible. This task can be optimally addressed by the "policy analyst," who could perform a pivotal role in insuring the understanding and use by policy makers of the products of policy research and in working with policy researchers to help focus their response to critical policy issues.

\section{INTRODUCTION}

Much of the discussion of fertility policies tends to focus on formal governmental actions and largely ignores the phenomena such policies are directed toward and the complex network of factors that interact to determine fertility levels. A brief review of some of those factors may help to provide a background against which both the potentialities and limitations of fertility policies may be more clearly seen.

Human reproduction is an exceedingly complex phenomenon in which genetic, physiological, psychological, and societal forces are all operative. The basic parameters are biologically established, but they are characterized by a certain looseness or "play" in the patterned processes that permits considerable modification by the concerted and cumulative actions of environmental, individual, and societal influences. We cannot yet alter the menstrual cycle so that ovulation occurs normally once a year rather than once a month, but we can block ovulation temporarily or permanently. And we cannot speed up gestation so as to produce a baby in five months instead of nine, but we can interrupt the process at any point. In short, we can tinker with individuals to alter biologically determined patterns but cannot change the species.

Genetic and physiological factors set conditions that make reproduction both certain and limited. Societal and psychological forces determine to a large extent when and where it will occur. As with 
biologically determined behavior, there is a good deal of "play" in societal mechanisms for controlling reproductive behavior that permits considerable variability and individual choice. Societies set rules governing sexual access, some of which-like incest taboos-are highly effective controls and others of which-such as proscription of sexual relations outside of marriage-are viewed as less stringent. The family, that universal institution into which most individuals are born and in which they spend much of their lives, is admirably designed to assure that reproduction occurs and that children are cared for during their long period of dependence and properly prepared for societal membership. Individuals have a choice about when they will have children and how many they will have, but the choices are made in a context of social pressures (and prior social conditioning) that assure a high degree of conformity to group expectations. In many countries, as Judith Blake (n.d.:279) puts it, "People make their 'voluntary' reproductive choices in an institutional context that severely constrains them not to choose non-marriage, not to choose childlessness, not to choose only one child, and even not to limit themselves solely to two children." The constraints vary with time and culture, but they are always present. The "universal human right" of every couple to choose the timing and the number of children they will have is a noble sentiment, but there is not a country in the world where it is not subject to highly effective societal and cultural constraints. And any policy measures intended to influence fertility will in turn be affected by the extent to which they are compatible or incompatible with the existing complex of shared beliefs, values, and customary practices.

As both a biological and a social phenomenon, human reproduction is affected by influences operating at any of three levels:

(1) biological-for example, shifts in nutritional status, disease states, general health status; surgical or chemical intervention;

(2) individual or personal-for example, changes in knowledge; shifts in social. economic, or marital status; acceptance of new beliefs or values; shifts in reference group identification; exposure to rewards or punishments;

(3) societal-for example, changing family relationships and roles; the development of a "singles culture" as in some Western cities; shifting roles and statuses of women.

The implication for fertility policy of this listing is that changes are harder to implement and less direct and certain in their effects on reproduction as one moves down the list. It is relatively easy to affect reproduction, especially to reduce or prevent it, by tinkering with 
individual organisms. It is much more difficult to change the attitudes and behaviors of a group of individuals; and it is exceedingly difficult to bring about a predictable change in a societal institution by deliberate and conscious policy measures. Institutions are responsive to policy initiatives, but their responses are usually slow and of ten different from those anticipated. The dominant and determining agency is the society, not the government: Government is but one among many institutional arrangements through which societies regulate their members-and their numbers. What a given government can do about fertility and what effects its policy measures have are substantially shaped by forces that are only partly subject to governmental control.

The complexity of fertility and the degree to which it is supported and promoted by solid social institutions and widely shared values make difficult the devising of adequate strategies for reducing it. If we ask the economists how it is to be done, they advise us to change the balance of costs and benefits of children: reduce the utilities and increase the costs and there will be fewer children born. The sociologists point to the long standing, deeply ingrained, and highly cherished social institutions and values that support fertility and they say that we shall have to change them. The psychologists direct us toward the need to find substitutes for the psychic rewards we get from children and to devise alternative ways of achieving the emotional supports and satisfactions that having and living with children provide. The physicians suggest that the way lies through increasing maternal and child health services, including family planning, and through reducing infant and child mortality and improving nutrition. The politician replies with his ringing declaration of unfettered reproduction as an inalienable human right and ignores the fact that the freedom of choice he defends is as mythical as the unicorn. The dedicated and zealous family planner holds that if we but provide widely enough the means of contraception and abortion, they will create their own demand. The biological scientists imply that the means of salvation will be found in improved contraceptive techniques. And, as the debate at the World Population Conference in Bucharest revealed, leaders of some Third-World countries. think that if the rich quit consuming the poor will stop breeding and that, in the words of the World Population Year slogan, if we take care of the people, population [read "fertility"] will take care of itself.

Whatever course may be adopted-and there are elements of merit and truth that deserve consideration in all the viewpoints listed aboveit will be well to remember that any policy or program intended to affect fertility will have to exercise its influence on reproduction sooner 
or later through one or another of three variables: sexual intercourse, conception, or gestation and parturition. These "intermediate variables," as they have been called, are the only direct means by which fertility change can be effected. Higher incomes, better education, different social institutions, new roles and statuses for women, modernization, improved health, and the other benefits of economic and social development do not themselves directly alter fertility. Any effect they have can come only through their capacity to change one or more of the intermediate variables.

Nearly twenty years ago Davis and Blake (1956) provided a classification of these means of fertility control. Their scheme, in slightly abridged form, is presented here to indicate how limited the means to fertility control are:

\section{Intercourse variables}

(a) Those governing the formation and dissolution of unions in the repro. ductive period.

(1) Age of entry into sexual unions.

(2) Proportion of women never entering sexual unions.

(3) Amount of reproductive period spent before, after, or between unions.

(b) Those governing the exposure to intercourse within unions.

(4) Voluntary abstinence.

(5) Involuntary abstinence.

(6) Coital frequency (excluding periods of abstinence).

\section{Conception variables}

(7) Fecundity or infecundity as affected by involuntary causes.

(8) Use or nonuse of contraception.

(9) Fecundity or infecundity as affected by voluntary causes (sterilization, medical treatments. etc.).

\section{Gestation variables}

(10) Involuntary pregnancy interruption.

(11) Voluntary pregnancy interruption.

Intercourse variables under heading (a) would seem to be directly and indirectly amenable to some influence from governmental policies; those under (b) are probably beyond the reach of public policy, although it could be interesting to speculate on the probable effects (if any) of a massive campaign to popularize Sexless Monday or Never on Even Days or a concerted abstinence movement such as Aris- 
tophanes described in Lysistrata. Conception variables are highly vulnerable to policy intervention. Gestation variables are perhaps less so but seem to respond differently depending on whether the policy is pro- or antipregnancy termination. Policies to inhibit deliberate pregnancy termination through making it illegal seem not to have been effective any where in the world, although the evidence on the Rumanian policy shift is not all in. On the other hand, policies and programs offering legal abortion have had significant demographic effects in Japan, Eastern Europe, and more recently in parts of the United States, and they are becoming more widely acceptable. A recent report (van der Tak, 1.974) states that by early 1974 abortion on request in the first three months of pregnancy had become legally available in 27 countries containing over half the population of the world.

If public policies are to affect fertility they have to do it, directly or indirectly, by changing behavior related to intercourse, conception, or gestation. To lose sight of that fact is to risk investing time and resources in actions that are not likely to have much payoff in fertility change. To keep it in sight means being aware, through theory or empirical evidence, of how any intended policy or program is expected to have an influence on these variables. If income distribution or improved nutrition or any other secondary or tertiary activity is intended to change fertility, those who advocate it should be prepared to describe and document the chain of linked stages by which the end result is expected to be reached.

\section{FERTILITY POLICY: CONCEPTS AND DEFINITIONS}

Any paper about fertility policies should make clear what it includes and excludes in such a term. Like some of the other portmanteau terms in common use-development, quality of life, social justice, human rights, for example-population policy is an imprecise concept that can mean as much or as little as anyone wants it to mean. There is little consensus in the community of scholars concerned with population matters about what is or is not population policy. Many who use the term do not bother to explain what they mean by it; those who do struggle toward a definition fight a losing battle against the complexities of the concept and produce definitions that are apparently too inclusive or too exclusive to have wide appeal among their colleagues and peers.

Assuming that we can agree with Webster's (1969:656) that a policy is "a definite course or method of action selected from among alternatives ... to guide and determine present and future decisions" and 
that a public or national policy is one adopted by a governmental agency, some questions still remain about what constitutes a population policy. For example:

Are both a statement of intent and an implementing mechanism necessary? Thailand for several years was offering contraceptive services on a national scale through the Ministry of Health, but there was no explicit statement of support for this action or an intention to influence fertility. Did the country have a population policy?

Must there be an explicit intention to change a demographic variable, or is any policy action that affects such a variable to be considered a population policy? If a rural development policy, such as the one being implemented in the Pahang River valley in Malaysia, attracts a sizable group of migrants from other parts of the country, is it a population policy?

Some distinguish two types of population policy-those that are population-influencing and those that are populationresponsive. A program to build more classrooms to accommodate growing numbers of students might be an example of the latter. Does it clarify or confuse matters to regard it as a population policy?

Does failure to act or to recognize a condition explicitly constitute a policy? Can a nation with a 3 percent annual growth rate, but with no statement recognizing growth as a problem and no program to do anything about it, be considered as having a pronatalist policy?

One of the more comprehensive recent attempts to clarify the concept of population policy is that of Clinton (1974), who distinguishes between decision and policy, calling policies "standing decisions or decisions intended to guide future decisions and actions" (p. 3) and rules out population-responsive policies as more properly called something else. Clinton would include as population policies only those that deal with one of the substantive areas of demography-fertility, mortality, or migration-and would not exclude those in which the effect was unintended. Thus he would reserve the term population policy for those policies "designed to be or which actually are population-influencing" (p. 6). Clinton's analysis is more thorough than most; but it still leaves a good many matters to be decided by conventional agreement among scholars and it drifts off toward am- 
biguity in admitting as population policy any governmental action that seems to have an effect, however unintended, unanticipated, and indirect, on any of the demographic variables.

Clinton would use the term population policy to refer only to the actions of governments. Berelson (1971), on the other hand, would include policies of cthnic groups, international bodics, or religious communities if they "intend or effect a non-trivial alteration in events" (p. 173). His major emphasis, however, is on governmental actions, and in his view either intentions or consequences may be used as criteria for inclusion as population policy.

Lowi (1972) defines policy as a general statement by some governmental authority defining an intention to influence the behavior of citizens by use of positive and negative sanctions. A policy, as he sees it, must possess the following characteristics: (1) an official expression of intentions concerning desirable or undesirable conduct; (2) a provision for inducements, positive or negative, or both; and (3) some provision of means for implementing the intentions and applying the sanctions (or inducements). Lowi makes the further point that it is impossible to have a government policy without having coercion. Coercion can be remote and indirect, can involve positive or negative sanctions, can be benevolent or malevolent, and can coerce some in order to be of explicit assistance to others; but policy is no less coercive because there are different forms of coercion, or because governments have a choice among types of coercion, among types of people to be coerced, and among the various sanctions to be employed.

Davis (1.971) views population policy as a deliberate at tempt, through governmental or quasi-governmental measures, to change or maintain the rate of population growth. Elements common to all population policies include intent to change or eliminate a particular demographic trend or condition, a presumption that the trend or condition is accurately known, a theory of how the intervention will alter the causes of the trend as well as a theory of how the redirected trend will improve the social and economic situation, and awareness that the consequence sought constitutes a collective goal.

Davis also makes the point that, whatever the demographic goal of a policy, it is always viewed as instrumental to a nondemographic goal. It follows that population policies must be interrelated in significant ways with other public policies as they affect the achievement of a society's aspirations and goals. It also follows, as Lowi notes, that expansion or introduction of new and serious policies aimed at fertility reduction may be at cross purposes with other public policies, which 
may have population relevance but not with specific intent. That is to say, there is potential political divisiveness that may ensue as a concomitant of any intentional policies to control population growth, for the intentional policies may cut across important existing welfare, taxation, and other policies and affect the many and profound interests already tied to those policies.

Selecting from among these and other definitional components and narrowing our focus from population in general to fertility, we define a fertility reduction policy as one that expresses an explicit intention to induce a change in fertility rates in a downward direction (the desired effect may be achieved directly or indirectly but the intent must be explicit) through governmental measures that are specified and with appropriate resources that are committed, in order to realize one or more societal values or goals. According to this definition any effort to "solve" a population problem by such means as improving the nutritional status of children, increasing the food supply, or reducing environmental pollution may constitute a policy, but it is not a fertility reduction policy. A family planning policy may or may not be a fertility reduction policy. It is not if it is explicitly aimed at such changes as improvement of maternal and child health, elimination of illegal abortion, improvement of family well-being, or modification of other nondemographic conditions. This may seem like semantic nitpicking, but given widespread reluctance to face the problems of rapid population growth, the strong and persistent pressures to divert fertility reduction measures into less difficult and politically and professionally more congenial goals-as exemplified by much of the debate at the World Population Conference in Bucharest-it is important to understand what is being talked about when a population policy or a fertility reduction policy is being discussed. We do not deny that a variety of policies may and indeed do have unintended effects on fertility or that such policies should be adopted or their influences studied. We merely want to emphasize the importance of being certain when a fertility reduction policy is being advocated or supported or adopted that it is indeed intended to reduce fertility.

From various definitions and descriptions of population policy, a set of characteristics can be abstracted that illuminate aspects of how such policies are formulated and how they operate. These would include the following:

1. They are public policies; that is, they represent governmental decisions bearing on the allocation of scarce resources for which there is competition. 
2. They are national in scope and intent, but implementation may be decentralized and applied differently in different subnational areas.

3. They are broad and general in that they are aimed at large segments of the national population. (The Indian family planning program, for example, is concerned with the 100 or so million married couples.) As Ilchman (1974) puts it, they are gross attempts to influence the behavior of large numbers of people through the use of rather limited repertoires of interventions.

4. They provide for some action mechanism, for some way of achieving the desired change.

5. They are macro-level in statement and intent, but results have to be obtained through micro-level changes in values and behavior.

6 . They are always instrumental to some other end. They are means, not ends.

POLICY MEASURES AMENABLE TO GOVERNMENTAL ACTION If fertility is to be brought under rational control-and it is increasingly apparent that sooner or later it will have to be if we wish to avoid having Malthus become an honored prophet-governments are the only agencies with sufficient control over resources and power to organize and lead the effort. But even governments are limited in what they can do, by lack of resources to meet competing and of ten conflicting claims, by inadequate technology, by lack of information or understanding, by bureaucratic rigidities, by public opinions and expectations, and by their nature as political and administrative institutions.

Governments are not omnipotent. The range of action options available to them is limited. The list can be longer or shorter depending on how general or how specific the category headings are, but the following is probably reasonably complete:

- Governments can pass and enforce laws and administrative regulations.

- They can operate service programs.

- They can manipulate systems of rewards and penalties.

- They can collect and disseminate information to shape public knowledge and opinion and perhaps influence collective values and norms. (They can also try to prevent the flow of information for the same reasons.) 
- They can marshal and allocate resources.

- They can engage in international activities, including war.

Each of these actions has implications for fertility-related behavior and all, with the possible exception of war, have been used by governments in attempts to influence fertility upwards or downwards. War directly affects fertility in several ways but has not been a deliberate instrument of fertility policy. It may be noted that Berelson (1974a) has compiled and discussed a similar list of what governments can do about population.

Governmental decisions and actions relating to fertility, as to other areas, are taken in the context of political, economic, ideological, and ethical constrain ts that circumscribe in varying degrees (depending on the country and the culture) the range of options available. Not all of the actions in the above list are feasible for adoption by any government at any given time. In assessing prospective policy measures, however, one should separate the question of potential effectiveness from that of their probable feasibility and acceptability, since, as Germain (n.d.) has noted, preoccupation with the latter inhibits the movement of potentially effective measures from the unacceptable category to the acceptable.

If the range of acceptable options is to be broadened, a start must be made on assessing the potential effectiveness of a variety of policy measures not now espoused, but which might be demonstrated, through experimentation and research, to be effective under certain conditions. As the reference to Davis (1971) indicates, among the elements common to all population policies is a presumption that the demographic trend or condition to be changed or eliminated is accurately known and that there exists a theory of how the intervention will alter the causes of the trend as well as a theory of how the redirected trend will improve the social and economic situation. For such "theories" to be meaningful they must be tested in research.

\section{RECENT POPULATION AND DEVELOPMENT POLICIES}

What governments have done recently in the area of fertility policy, especially fertility reduction policy, is well summarized in a series of Population Council Reports (Nortman, 1974; Stamper, 1973; Tietze and Dawson, 1973; Berelson, 1974a) and other publications (Berelson, 1974b; van der Tak, 1974); they will not be reviewed here. The most common type of policy, as might be expected, is family planning, although not all countries offering family planning services regard 
them as components of a fertility reduction policy. Population education programs, when specifically aimed at inculcating norms about responsible parenthood and small family size, may be regarded as indirect attempts toward implementing a policy of fertility reduction. Such programs have recently become popular with a number of governments; like family planning programs, they are generally high in political viability and ethical acceptability, to use Berelson's terms. The list of other policy-based efforts is short: vasectomy camps in India, the educational bond scheme in Taiwan, the incentive-disincentive program in Singapore, the slow spread of permissive abortion legislation, the late marriage policy in China.

The number and variety of governments that have espoused family planning programs, even though not always as a population policy measure, is of course in itself a dramatic and significant phenomenon. But Stamper's (1973) survey of population policy in development planning showed that only 18 out of 70 developing countries included -in the study supported, in their development plans, policies and programs to reduce fertility. (Additional countries moved into this category after the study was done.) Of these 18 , some actually have programs to reduce fertility, others have merely recommended such programs, and only a few have included measures other than family planning.

One approach to the problem of excessive fertility that has enjoyed substantial popularity is the notion that the employment of policy measures to promote economic and social development and modernization will surely bring in their wake fertility decline. In short, it is argued, development policy is fertility policy. Demeny (1974:8) has described this view thus:

One version of this position advocates exclusive concentration on development policy as narrowly defined, that is without any direct attention to fertility effects as such. It is simply assumed, although the assumption often is only implicit, that correct development policies will also lead to fertility behavior that is just right for the society in question. Alternatively, it is assumed that the task of society is to adjust to whatever level of demographic behavior development policies generate. In either case, fertility as such is not a policy variable.

In effect, acceptance of this position does away with the need for governments to adopt measures directed toward the fertility problem. A more sophisticated version of this position maintains that the "right mix" in development policies, which would include the goal of more equitable distribution of income as well as other components of social and economic well-being, would produce a major impact on fertility 
decline, but it calls also for fertility reduction policies, including family planning, as they have been defined here (Rich, 1973; Kocher, 1973). Demeny (1974:9) contends, however:

Development plans represent a scries of compromiscs between feasible degrees of satisfying a variety of desires. The introduction of fertility policy in to development planning begins when the mix of development policies that is considered best without regard [italics in original] 10 fertility effects is actually modified because of an intended extra fertility impact. ... Given the existing state of the art of development planning and given the inadequate conceptual framework for analyzing population problems, it is, in fact. doubtful whether arguments based on fertility effects of development policies are ever strong enough appreciably to modify the mix of development measures that planners would otherwise propose.

Actually, evidence has been produced by Coale, Demeny, and others that fertility decline has taken place under a wide range of social and economic conditions. Allan Sweezy (1973), considering the history of fertility decline in southern and eastern Europe, reinforces this evidence: "Sharp and sustained fertility declines have occurred in countries that were poor, predominantly agricultural, relatively uneducated, and still suffering from high mortality. If they have occurred before there is nothing, at least in these conditions, to keep them from occurring again elsewhere" (p. 12).

Development policies are of course aimed at highly valued goals in their own right, but not all development policies are fertility reduction policies. Some may indeed ultimately affect fertility, but the relationslip can hardly be regarded as a simple one-way affair or the outcome as inevitable. Sustained high fertility rates can clearly constitute impediments to the consummation of development goals. Consequently, the implementation of policies deliberately aimed at achieving sustained fertility decline can be seen as a necessary if not sufficient condition of progress in development, just as progress in development may contribute to fertility reduction. As Teitelbaum (1974:756) has said "... more than a decade of experience is available to document the proposition that programs directed to economic development and to population growth are mutually supportive; there is no empirical warrant for the 'either/or' type of argument." If sustained fertility decline is to be achieved in the developing world. it will be brought about not only by effective development programs and improved family planning programs, but also by the search for and implementation of viable population policies that can serve as effective complements to existing programs. No one set of policies will serve for all countries, of course; although countries may learn from one another, each government will have to develop its own policies, based on what can be 
effective in the national setting and ultimately on what can become acceptable. These considerations, in turn, will require policy analysis and research appropriate to that setting.

A review of what governments have done to reduce fertility would make it apparent that no government is doing all it could. The proportion of national budgets expended for fertility reduction is very small; the number of approaches being followed is limited; there is little or no research in to the possible unintended effects on fertility of other kinds of policy actions and less concern with how these effects might be limited or enhanced. Everywhere, for example, virtually all births occur within marriage or in stable unions that have most of the characteristics of marriage except legal endorsement. But very few countries have tried to design marriage policies that might operate to minimize the large, but not always intended, pronatalist influence of that institution.

A serious antinatalist program would seem logically to require policy actions affecting three areas:

1. Measures to delay entrance into marriage and to keep as low as possible the proportion of women married. On the assumption that not many women are likely to have children outside of marriage, a variety of measures could be adopted to make entrance in to marriage more difficult and to develop satisfying alternatives for at least a part of the reproductive period. Such measures might include laws raising and enforcing the age at which marriage could be entered; measures to make entrance into marriage more difficult-for example, high license fees graduated perhaps by age, with extremely high fees for the young that taper downward with age; compulsory waiting periods after a license is obtained; premarital means tests; compulsory premarital examinations on population and contraceptive knowledge; easier divorce (if accompanied by satisfactory arrangements for caring for children); two-tier marriages-one type for companionship, one type for reproduction: special welfare and employment services for widows and divorcees in their reproductive age period; special emphasis on jobs for single women; educational programs for teenage girls; single-sex youth camps or corps; a year or two of compulsory national service for both sexes between the ages of, say, 18 and 20.

2. Measures to induce people to want to have small families. These might include a variety of informational and educational programs; economic incentives and disincentives including differential taxes; transfer of more child-raising costs to parents and to local commu- 
nities; social security provisions for the elderly; mobilization and use of civil administration officials; community forums; community incentives; mobilizing of community opinion in favor of small families.

3. Measures to help those who want to avoid a pregnancy or a birth to do so. The measures here are familiar, but they could be expanded and strengthened almost anywhere: family planning programs; subsidized contraceptives and services; commercial advertising and distribution of contraceptives; free elective sterilization for both males and females; legal abortion and free abortion services.

The items listed under each heading are illustrative, and not all of them are politically or economically or ethically feasible in all countries. But situations are changing and governments are finding that they can do things that a few years ago they thought they could not do. The importance of the list is not in the specific measures mentioned but in their indication that (1) a greater variety of approaches is possible and desirable, and (2) any measures intended to affect fertility will be successful only to the extent that they operate through one or another or some combination of the three areas listed: exposure to the risk of pregnancy, motivation and acceptance of responsibility for fertility limitation, and prevention of conception or birth.

An area of critically needed research is that which could demonstrate the anticipated or actual relationship between any given fertility policy component and any of these intermediate variables. Especially useful to policy makers would be studies producing estimates of the likely and maximum effect that might be expected from any contemplated policy action at a given level of input, along with estimates of what the political and economic costs would likely be. Such studies would not be easy research; and given the great number of uncontrollable factors that influence fertility in one way or another, perhaps no very accurate estimates are possible at reasonable costs. But it should be possible and feasible to make some estimates of the maximum result that could occur under the most favorable conditions. What difference would it make, for example, if 10 percent of the women between, say, 18 and 43 were not married at any given time? What would be the effect on fertility if the average age at marriage were increased by two years? How much, if at all, would fertility be affected if most of the costs of education were transferred to local communities? Even rough estimates would be useful.

Many development policies can be expected to have consequences 
for fertility, but the developing countries cannot depend solely on their development efforts to bring down fertility rates even if "development" proceeds at an optimal pace (itself a problematic assumption). Moreover, the desired demographic effects of population policies have a long lag-time before they appear because of the momentum already present in the age structure of most developing countries, which guarantees substantial population increase no matter what action is taken now. But the eventual size of the developing countries' populations will be determined by the date on which fertility declines to the low levels characteristic of the developed countries. There is need, therefore, to identify and assess the range of alternative population policy options that could be adopted and implemented by governments now, in addition to family planning, both to cope with the consequences of the future population growth that will be upon us, and to slow down that growth as soon as possible. The remainder of this discussion offers some thoughts on what might be done to address the latter task.

\section{POLICY ANALYSIS}

Concern over the problem of how to reach policy makers with the findings of social research, or how to improve communication between producer and consumer so that research findings are understood and used, has been expressed repeatedly in the population literature. It is a concern that is hardly unique to the population field. A recent study by Nathan Caplan (Institute for Social Research, 1974) indicates that of the billions of dollars spent annually by the U.S. government on scientific research and development, relatively little of the information gathered has any impact on the decisions of key policy makers. Caplan reports that ". . . government of ficials don't need to be sold on the usefulness of scientific information ... but . . of ten lack the skills and proper orientation to put scientific knowledge to good use" (p. 2).

In the developing world, it is not just a question of how to put to use knowledge about the consequences of population growth, but also whether policy makers (including planners) appreciate the need for such knowledge, which is largely lacking as well. More urgent than the need for putting research to use, important as this is, is the need to convince government leaders of the grave consequences of rapid population growth and to encourage them to explore a range of policy options for reducing it. Conviction and motivation on the part of leaders are necessary conditions for serious consideration of the range of al- 
ternative policy options that could be developed through analysis and research. Presumably most leaders are genuinely concerned with promoting the economic and social development of their countries (a presumption that may be questionable but must be regarded as reasonable). If so, it should be possible to gain their conviction and motivation by documenting empirically the effects of population dynamics on development goals and by producing evidence of relationships between particular policy measures and their probable consequences for effective fertility reduction-provided that an effective means of communicating this evidence is available.

The World Population Conference and the subsequent regional conferences may help to sensitize world leaders to the consequences of future population growth and to mobilize their support for new policies; but the empirical demonstration, in forms that policy makers can work with, of "alternative approaches .. . specifying potential differences in the intention, effect, and cost of various programs" (Etzioni, 1971:8) is the task of policy analysis and research. It cannot be accomplished by conferences. The task is at least threefold: (1) to demonstrate the impact of population growth on development goals; (2) to assess the population effects, explicit and implicit, of current and proposed development policies and programs; and (3) to identify, design, and test the potential effectiveness and feasibility-leaving for subsequent consideration the question of acceptability-of alternative policy options that can facilitate the realization of development goals. There is need for analysis not only of the effects and costs of taking alternative actions, but also of the effects and costs of not taking them. As Davis (1971:6) has said, "Once the question of the consequences of population change is seriously raised, a failure to take any action is itself a population policy." and it thus becomes a proper object for policy analysis and research.

This is a formidable task, beset with many conceptual and methodological complexities. It clearly will require long-term research efforts on many fronts, involving all of the relevant social science disciplines. To build the necessary data base will require employment of all the tools available to social-science research-econometrics and mathematics, large-scale surveys, social experiments and evaluated demonstrations. longitudinal and cross-cultural studies, and so on. But while this is being undertaken, there still remains with us an acute need (1) to bring to the policy maker an understanding of what is already known that is of policy relevance: (2) to engage policy makers and researchers in a common effort to identify the key questions that are 
researchable and need to be answered; and (3) to provide policy makers with continuing consultation, based on the best available knowledge, of what options may be open to them, together with their anticipated effects, as they engage in the decision-making process.

An increasing number of social scientists, in both the developed and the developing worlds, are undertaking research on problems relevant to population policy: but their contacts with policy makers, with some exceptions, are likely to be sporadic and of limited duration. They are not in a position to respond appropriately or adequately to the array of needs indicated. There is a place here for the "policy analyst," who can play a pivotal role in performing these necessary functions. Variations of this theme have been proposed in a number of writings, including those of Saunders and Hardee (1972), Baldwin (1973), and, in a more limited context, Blaise (1974). It is not suggested here that a new professional role of "communicator" or "interlocutor" be created in the person of the policy analyst, but that the policy analyst be a social scientist, preferably a senior person who has engaged in policy research and has the authority and knowledge to cope with the policy maker's questions and needs. (We are using the term "policy analyst" here to designate a particular role-set vis-d-vis policy makers, but in fact policy analysis is an integral part of policy research. and the policy analyst is indeed a policy researcher who would take on the special role of change agent for policy makers. By "policy makers" we mean government officials who are senior staff in national planning offices and ministries and are responsible for public policy intervention relevant to population grow th.)

The policy analyst, if he-or she-is to respond effectively to the needs indicated above, will have to learn how the world looks to policy makers and to take into account their perceptions and values, as well as to be critical of their assumptions if they are at odds with demographic realities. Dr. Samuel Darling, the malariologist who worked on the Panama Canal project, is reported to have said, "If you wish to control mosquitoes, you must learn to think like a mosquito." Similarly, if you wish to influence policy makers, you must learn to think like them. Given the urgency of population issues, the policy analyst will frequently have to make assessments of alternatives and recommendations for action without waiting for full documentation or ultimate "proof" from research findings. He must of course base his decisions on the best available knowledge, while recognizing the deficiencies of that knowledge, since policy will be made or unmade regardless of the deficiencies. As Coleman has stated, "Partial informa- 
tion available at the time an action must be taken is better than complete information after that time" (1973:1).

If the policy analyst and his associates are to make effective contributions along the lines suggested above, they will have to be located as close as possible to the top authority in a government's policymaking apparatus. More important than the actual physical location is necessary support from and access to policy makers. In some countries the indicated location may be a national planning of fice, as in Thailand and Malaysia, or it may be national planning commissions or particular ministries, depending on where the critical decisionmaking power lies. In any case, policy analysts should be located close to the policy makers, but at the same time be sufficiently independent to allow them to undertake critical analyses.

\section{POLICY RESEARCH}

Like any other policy research, social research oriented to population policy formation should be concerned with mapping alternative approaches and with specifying potential differences in the intention, effect, and cost of various programs. At the same time, it must respond to the accepted canons of scientific endeavor. For present purposes, policy research is to policy analysis as basic research is to policy research. Policy analysts should bring to their work with policy makers the data base and relevant insights generated by the efforts of policy research, just as policy researchers bring to their work knowledge of basic research in the social sciences. Etzioni puts it well: "While basic research aims chiefly to uncover truth, policy research seeks to aid in the solution of fundamental problems and in the advancement of major programs" (1971:8).

As indicated above, population policy research needs to assess the fertility effects of existing policies and programs, as well as to generate new knowledge that can facilitate the identification of additional fertility policy options and the assessment of their potential effectiveness. Central to the conduct of policy research is the principle that some variables are subject to policy manipulation while others are not. Policy research, if it is to have utility for both researchers and policy makers, must focus on those variables which are relatively malleable (or potentially malleable if situations were to alter), such as perceptions, attitudes, and certain kinds of behavior, rather than on those which are difficult or virtually impossible to change, such as sex, age, educational status, or ethnicity.

To engage here in setting priorities for population policy research 
would be inconsistent with the stance taken earlier in this discussion. Each country will have to develop its own set of viable policies based on policy analysis and research appropriate to that setting, and policy makers and researchers will have to develop a common perspective in identifying the key questions that can be answered through research. But it may be pointed out that whatever priorities are set for research, where the regulation of fertility is of prime concern the research will have to focus on determinants that are centrally relevant to the effective long-term regulation of fertility. Within this broad area, research will also have to focus, as Fawcett (1974) has stated, on "mutable determinants"-that is, those social-situational, cultural, and psychological factors that can be identified as susceptible to change through policies and their implementation. Examples of such determinants are to be found in the various lists of "beyond family planning" proposals that have appeared in the literature-lifting pronatalist coercions, introducing incentives and disincentives, providing genuinely alternative career roles for women, changing normative preferences for number and sex of children, shifting age at marriage; changing the perceived balance of satisfactions and costs of having children, and so on. Most of these have yet to be subjected to systematic research and experimentation in a variety of cultural, social, and political settings to ascertain their potential feasibility and effectiveness in reducing fertility, and to document the causal relationships involved. It is not at all clear, of course, whether or not some of these proposals may involve variables that are relatively more or less mutable, but there is no better way of finding out than by subjecting them to research. One alternative, where research is not immediately possible, is imaginative speculation that could lead to empirical testing; but failing this the only other alternative is doing nothing about the proposals at all, in which case they will certainly wither away as options. In any case, the research, where it is attempted, must explicitly focus on fertility effects as the dependent variable.

That the definition and implementation of research priorities should be undertaken at individual country levels by local researchers in conjunction with their own policy makers should not obscure the fact that relevant literature and experience developed elsewhere may be helpful to them in their own endeavors. For that reason, provision for comparative studies with researchers in other countries can only be advantageous. Such studies provide a kind of perspective, to be gained from comprehensive examination of the range of experience and policy options, in a series of countries, that can undoubtedly facilitate 
making better decisions on such issues in one's own country. There are at least two major program efforts now going forward in the developing world to develop multidisciplinary comparative research, each with its own set of regional priorities, focused on population policy issues. One is the consortium of social science research centers in Latin America coordinated by the Latin American Demographic Center (CELADE), the other the recently established group of social scientists in East and Southeast Asia, based at the Korean Institute for Research in the Behavioral Sciences (KIRBS).

\section{CONCLUSION}

This discussion has been primarily concerned with the development of capability in research and analysis that will help to provide an appropriate and effective knowledge base that can be shared with policy makers for the formulation of policy approaches to fertility. Policy approaches to population distribution and to the consequences of rapid population growth are of course equally important but are outside the scope of this paper. Nevertheless, there is a critical need for long-term planning and concomitant research to provide the economic infrastructure, to guide population distribution, and to find viable patterns of land use and labor for national populations on their way to doubling in size. The need is especially acute for urban populations, which may grow to five times their present size before the end of the century. In the present context, it may be noted that systematic efforts to identify what social, cultural, and economic situations will look like several decades from now would also enhance the determination of planners and policy makers to help reduce fertility as rapidly as possible.

The task that confronts policy analysis and research is complex and formidable. It calls ultimately for the systematic assessment of the effects of present and prospective policy measures on actual demographic behavior in ways that can be directly useful for policy formation. Social science research on the relevant variables has been quite uneven and far from definitive (see McGreevey et al., 1974). This is hardly surprising, when one considers that much of the research has been atheoretical and essentially descriptive. The increasing interest in population on the part of political scientists, psychologists, and anthropologists in both the developed and the developing countries should serve to broaden the range of policy issues and options meriting study and to generate increasing sophistication in the concepts and methods employed in policy research. 
It is important to keep in mind that policy analysis and research in general as an area of concern to social scientists is itself a relatively recent phenomenon. The social sciences have been primarily concerned with their own needs for disciplinary development, which is perhaps as it should be. The conceptual frames and methods they have acquired in the process do not lend themselves easily to the assessment of present and prospective public policies. In reviewing the case for policy research, however, James Q. Wilson writes:

If this is the case, on what grounds can anyone defend such policy-evaluating social science as exists? In part, because some studies do provide answers, even when judged by the most rigorous standards. ... But in large part social science evaluations, and the debates over them, are useful because they expose the complexities of a problematical situation, extend the range of possible explanations for those conditions, increasc our awareness of the unintended as well as intended oulcomes of any policy intervention, and stimulate us to reflect on the inadequacies of our own preconceptions about the matter (Ford Foundation, 1974: Appendix 1).

The Third Bellagio Conference on Population, which in May 1974 brought together high-level representatives from all of the major donor agencies concerned with the field, affirmed an overwhelming consensus among the participants that there is a need for rapidly increasing the amount and pertinence of social research to underpin population policies (Rockefeller Foundation, 1974). The participants called for efforts to increase the number of social scientists in the developing countries, to assure them of career opportunities in policy-oriented research, to use fully and wisely the growing social science capability in the developing countries, and to provide adequate support for the building of institutions and international networks based on indigenous initiatives. The principal point of the present discussion, however, is that for all of this effort to make a pivotal impact on social science contributions to policy formation will require a linkage between policy makers and policy researchers, a linkage that can be implemented by what has been described here as policy analysis. In working with policy makers, the policy analyst can insure understanding and use of the products of policy research. And in working with policy researchers in the universities and possibly in international consortia, the policy analyst can help to focus their response to critical policy issues and to translate academic research into policy terms. 



\section{REFERENCES}

Baldwin, C. Stephen

1973 Population policy: possible strategy for new development.

Unpublished paper, Population Council, New York.

Berelson, Bernard

1971 Population policy: personal notes. Population Studies 25:173-182 (July).

1974a An evaluation of the effects of population control programs. Studies in Family Planning (January):2-12.

1974b World Population: Status Report 1974. Reports on Population/ Family Planning, no. 15. New York: Population Council.

Berelson, Bernard, ed.

1974 Population Policy in Developed Countries. New York: McGraw-Hill.

Blaise, Hans C.

1974 Management issues in family planning programs: knowledge and action. Paper prepared for ECAFE Regional Seminar on the Rolc of Surveys and Studies for Family Planning Programme Management and Development, Bangkok, 28 January-9 February 1974.

Blake, Judith

n.d. Fertility control and the problem of voluntarism. International. Population and Urban Research, Reprint no. 492. Berkeley: University of California.

Clinton, Richard L.

1974 The decisional environment: knowledge and attitudes of elites as a determinant of antinatalist policy formation. Paper prepared for a Battelle Population Study Center Workshop, Seattle, May 1974.

Coleman, James

$1973^{\circ}$ Ten principles governing policy research. Footnotes (March). American Sociological Association.

Davis, Kingsley

1971 The nature and purpose of population policy. In Kingsley Davis and Frederick G. Styles, eds., California's Twenty Million. Population Monograph Series, no. 10. Berkeley: University of California. 
Davis, Kingsley, and Judith Blake

1956 Social structure and fertility: an analytic framework. Economic Development and Cultural Change 4(3):211-235 (April).

Demeny, Paul

1974 Population policy: the role of national governments. Paper presented at the First Regional Population Conference, ECWA, Beirut, 18 February-1 March 1974.

Etzioni, Amitai

1971 Policy research. American Sociologist 6:8-12 (June).

Fawcett, James T.

1974 Social and psychological aspects of fertility: issues and priorities. Paper prepared for ECAFE Expert Group Meeting on Social and Psychological Aspects of Fertility Behavior, Bangkok, 10-19 June 1974.

Ford Foundation

1974 Studies in racial, cultural, and political pluralism. Information Paper, Division of National Affairs (May). New York.

Germain, Adrienne

n.d. Fertility control in the Third World: where do we go from here? Unpublished paper, Ford Foundation, New York.

Ilchman, Warren F.

1974 Population knowledge and population policies. Paper prepared for a Battelle Population Study Center Workshop, Seattle, May 1974.

Institute for Social Research

1974 Science is seldom put to good use by U.S. officials. ISR Newsletter 2(1):2 ff.

Kocher, James E.

1973 Rural Development, Income Distribution, and Fertility Decline. New York: Population Council.

Lowi, Theodore J.

1972 Population policies and the American political system. In Richard Clinton et al., eds., Political Science in Population Studies. New York: D.C. Heath \& Co.

McGreevey, William P., et al.

1974 The Policy Relevance of Recent Social Research on Fertility.

Occasional Monograph Series, no. 2 (September), Interdisciplinary 
Communications Program. Washington, D.C.: Smithsonian Institution.

Nortman, Dorothy

1974 Population and Family Planning Programs: A Factbook. Reports on Population/Family Planning, no. 2 (sixth edition). New York: Population Council.

Rich, William

1973 Smaller Families through Social and Economic Progress. Monogräph no. 7. Washington, D.C.: Overseas Development Council.

Rockefeller Foundation

1974 Working Papers: Third Bellagio Conference on Population (June). New York.

Saunders, Lyle, and J. Gilbert Hardee

1972 Rationalc and suggestions for establishing a population planning unit: Malaysia. Paper prepared for the Government of Malaysia, August 1972.

Stamper, Maxwell

1973 Population Policy in Development Planning: A Study of Seventy Less Developed Countries. Reports on Population/Family Planning, no. 13. New York: Population Council.

Sweezy, Allan

1973 Recent Light on the Relation between Socioeconomic Development and Fertility Decline. Caltech Population Program Occasional Papers.

Teitelbaum, Michacl S.

1974 Population and devclopment: is a consensus possible? Foreign Affairs (July):742-760.

Tietze, Christopher, and Deborah A. Dawson

1973 Induced Abortion: A Factbook. Reports on Population/Family Planning, no. 14. New York: Population Council.

van der Tak, Jean

1974 Abortion, Fertility, and Changing Legislation: An International Review. New York: D.C. Heath \& Co.

Webster's Seventh New Collegiate Dictionary

1969 Springfield, Massachusetts: G. \& C. Merriam Co. 

No.

3 Husband-wife interaction and family planning acceptance: a survey of the literature, by Florangel Z. Rosario, November 1970, 21 pp.

9 Linkages of intrinsic to age-specific rates, by Nathan Keyfitz, December 1970, 33 pp. [Now available as Reprint 14.]

10 Methods of demographic estimation for statistically underdeveloped areas, by Paul Demeny, January 1971, 149 pp. [Now available as Reprint 17.]

12 Interpersonal communication and the diffusion of family planning in West Malaysia, by James A. Palmore, Paul M. Hirsch, and Ariffin bin Marzuki, March 1971, 33 pp. [Now available as Reprint 13.1

15 Measuring mortality: a self-teaching guide to elementary measures, by James A. Palmore, May 1971, revised June 1973,61 pp.

16 Measuring fertility and natural increase: a self-teaching guide to elementary measures, by James A. Palmore, May 1971, revised October 1972, 81 pp.

18 On aggregative economic models and population policy, by Geoffrey McNicoll, October 1971, 87 pp.

19 Households, families and friends in a Hawaiian-American community, by Alan Howard, November 1971,117 pp.

21 Multivariate analysis of areal fertility in Honolulu, by Chai Bin Park, March 1972, 39 pp.

23 A model for the age distribution of first marriage, by Griffith M. Feeney, April 1972, 31 pp.

24 Optimal population policy, by W. Brian Arthur and Geoffrey McNicoll, May 1972, 54 pp.

25 Legal regulation of population movement to, from, and within the United States-a survey of current law and constitutional limitations, by Peter Maggs, June 1972, 58 pp.

26 Spatial patterns of socio-economic structure and change in the Philippines, 1939-60, by Roland J. Fuchs and Telesforo W. Luna, Jr., August 1972, 55 pp.

27 Representation of national and regional political units in a computerized world future model, by Peter Maggs; October 1972, 51 pp.

28 The demographic situation in Indonesia, by Geoffrey McNicoll and Si Gde Made Mamas, December 1973, 68 pp.

29 The demographic situation in the Republic of Korea, by Lee-Jay Cho, December 1973, 52 pp.

30 Demographic research in Japan, 1955-70: a survey and selected bibliography, by $Y$. Scott Matsumoto, April 1974, 88 pp.

31 The demographic situation in Hawaii, by Robert W. Gardner and Eleanor C. Nordyke, June 1974, 120 pp.

32 The value of children in Asia and the United States: comparative perspectives, by James T. Fawcett et al., July 1974, 80 pp. 


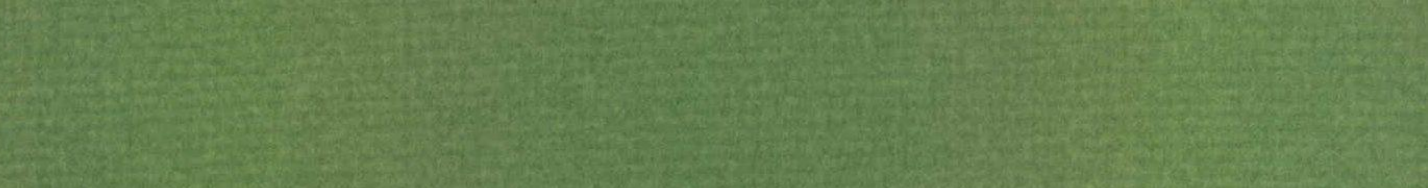

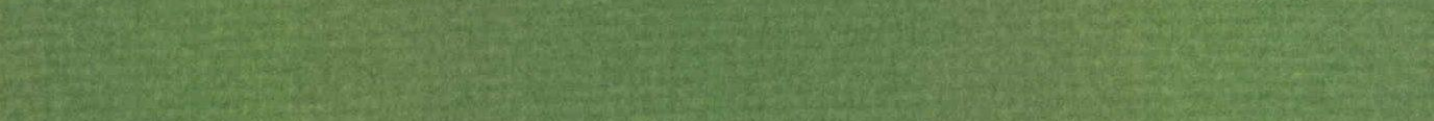
1. 15. P3.

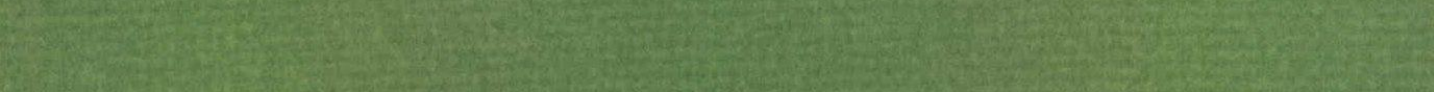

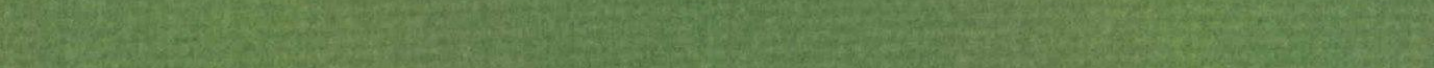

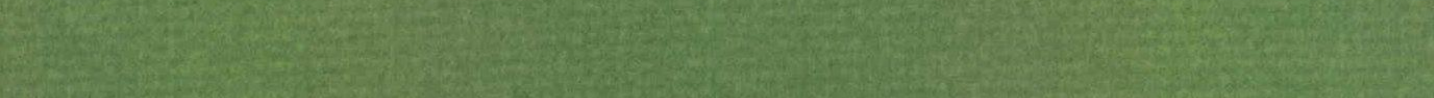

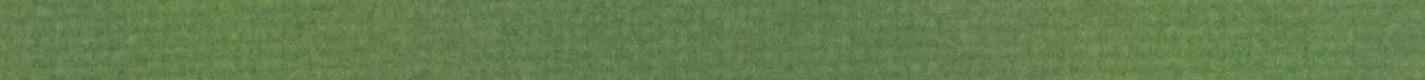
W. W.

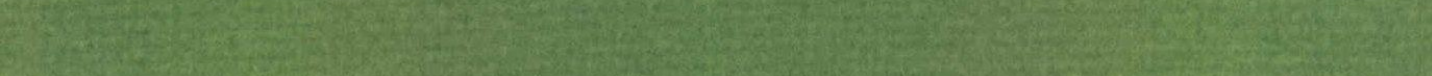

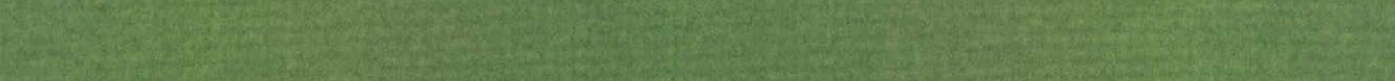

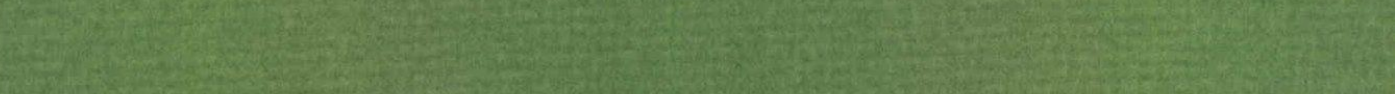
200 .

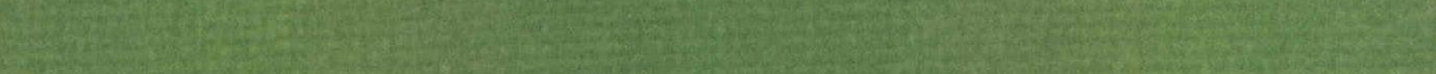
the (2)

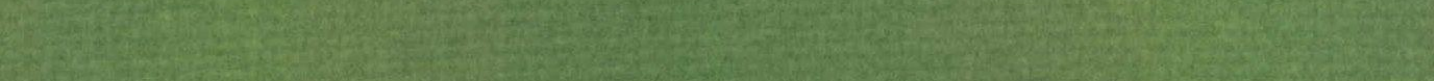

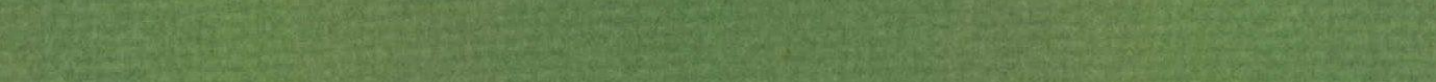

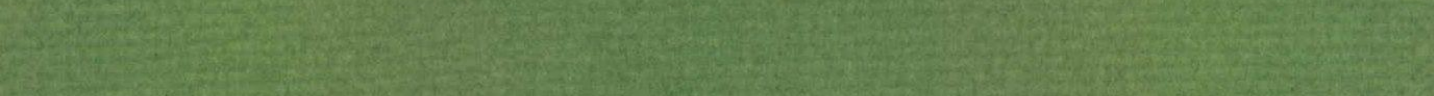

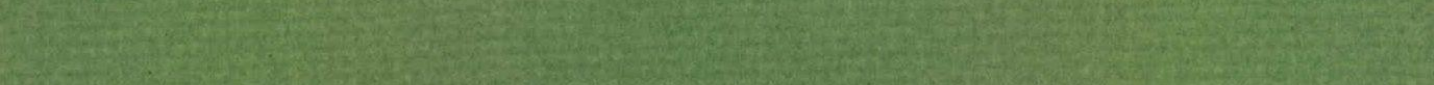
H. He. S.

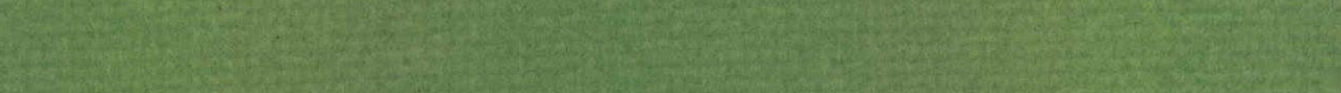
150.0.

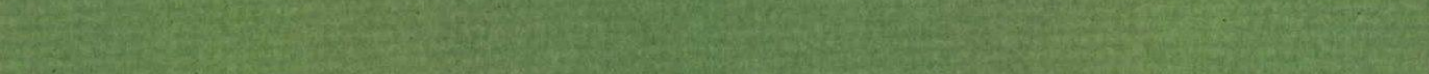
C. 20.6. 2.

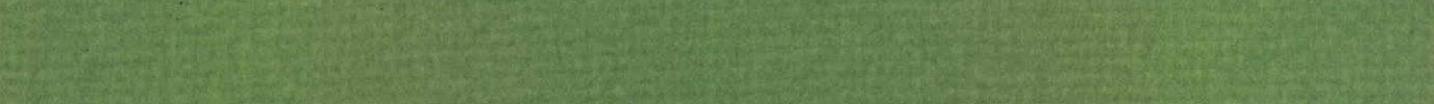
W.t.

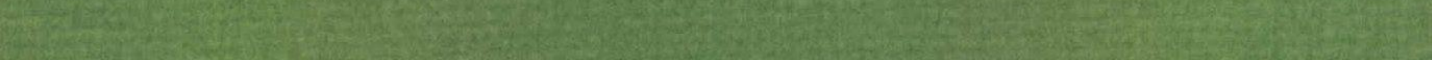
13.2.

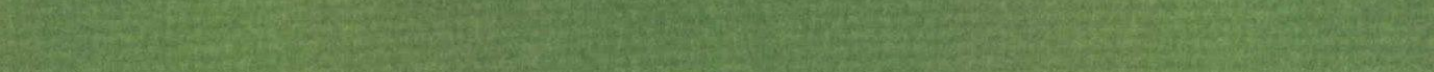

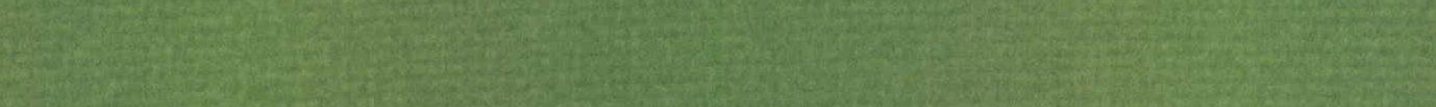
W. 
$x_{1}$ 